\title{
Static Response of Functionally Graded Material Plate under Transverse Load for Varying Aspect Ratio
}

\author{
Manish Bhandari ${ }^{1}$ and Kamlesh Purohit ${ }^{2}$ \\ ${ }^{1}$ Jodhpur Institute of Technology, Jodhpur, Rajasthan 342003, India \\ ${ }^{2}$ Jai Narain Vyas University, Jodhpur, Rajasthan 342005, India \\ Correspondence should be addressed to Manish Bhandari; manish.bhandari@jietjodhpur.com
}

Received 31 December 2013; Revised 2 June 2014; Accepted 4 June 2014; Published 30 June 2014

Academic Editor: Yanqing Lai

Copyright (c) 2014 M. Bhandari and K. Purohit. This is an open access article distributed under the Creative Commons Attribution License, which permits unrestricted use, distribution, and reproduction in any medium, provided the original work is properly cited.

Functionally gradient materials (FGM) are one of the most widely used materials in various applications because of their adaptability to different situations by changing the material constituents as per the requirement. Nowadays it is very easy to tailor the properties to serve specific purposes in functionally gradient material. Most structural components used in the field of engineering can be classified as beams, plates, or shells for analysis purposes. In the present study the power law, sigmoid law and exponential distribution, is considered for the volume fraction distributions of the functionally graded plates. The work includes parametric studies performed by varying volume fraction distributions and aspect ratio. The FGM plate is subjected to transverse UDL (uniformly distributed load) and point load and the response is analysed.

\section{Introduction}

The material property of the FGM can be tailored to accomplish the specific demands in various engineering utilizations to achieve the advantage of the properties of individual material. This is possible due to the material composition of the FGM which changes sequentially in a preferred direction with a predefined function. The thermomechanical deformation of FGM structures has attracted the attention of many researchers in the past few years in various engineering applications which include design of aerospace structures, heat engine components, and nuclear power plants. A huge amount of literature has been published about the thermomechanical analysis of functionally gradient material plate using finite element techniques. A number of approaches have been employed to study the static bending problems of FGM plates. The assessment of thermomechanical deformation behaviour of functionally graded plate structures considerably depends on the plate model kinematics. Praveen and Reddy reported that the response of the plates with material properties between those of the ceramic and metal is not necessarily in between to the responses of the ceramic and metal plates [1].
Reddy reported theoretical formulations and finite element analysis of the thermomechanical, transient response of functionally graded cylinders and plates with nonlinearity [2]. Cheng and Batra developed a solution in closed-form for the functionally graded elliptic plate rigidly clamped at the edges. It was found that the in-plane displacements and transverse shear stresses in a functionally graded plate do not agree with those assumed in classical and shear deformation plate theories [3]. Reddy formulated Navier's solutions in conjunction with finite element models of rectangular plates based on the third-order shear deformation plate theory for functionally graded plates [4]. Sankar and Tzeng solved the thermoelastic equilibrium equations for a functionally graded beam in closed-form to obtain the axial stress distribution [5]. Qian et al. analyzed static deformations, free, and forced vibrations of a thick rectangular functionally graded elastic plate by using a higher order shear and normal deformable plate theory and a meshless local Petrov-Galerkin (MLPG) method [6]. Ferreira et al. presented the use of the collocation method with the radial basis functions to analyze several plate and beam problems with a third-order shear deformation plate theory (TSDT) [7]. Tahani et al. developed 
analytical method to analyze analytically the displacements and stresses in a functionally graded composite beam subjected to transverse load and the results obtained from this method were compared with the finite element solution done by ANSYS [8]. Chi and Chung evaluated the numerical solutions directly from theoretical formulations and calculated the results using MARC program. Besides, they compared the results of P-FGM, S-FGM, and E-FGM [9, 10]. Wang and Qin developed a meshless algorithm to simulate the static thermal stress distribution in two-dimensional (2D) functionally graded materials (FGMs). The analog equation method (AEM) was used to obtain the equivalent homogeneous system to the original nonhomogeneous equation [11]. Shabana and Noda used the homogenization method (HM) based on the finite element method (FEM) to determine the macroscopic effective properties which lead to the same thermomechanical behaviour as one of the materials with the periodic microstructure [12]. Mahdavian derived equilibrium and stability equations of a FGM rectangular plate under uniform in-plane compression [13]. Zenkour and Mashat determined the thermal buckling response of functionally graded plates using sinusoidal shear deformation plate theory (SPT) [14]. Alieldin et al. proposed three transformation procedures of a laminated composite plate to an equivalent single-layer FG plate. The first approach is a curve fitting approach which is used to obtain an equivalent function of the FG material property, the second approach is the effective material property approach, and the third approach is the volume fraction approach in which the FG material property varies through the plate thickness with the power law [15]. Na and Kim reported stress analysis of functionally graded plates using finite element method. Numerical results were compared for three types of materials. The 18-node solid element was selected for more accurate modeling of material properties in the thickness direction [16]. Vanam et al. analyzed the static analysis of an isotropic rectangular plate with various boundary conditions and various types of load applications. Numerical analysis (finite element analysis, FEA) has been carried out by developing programming in mathematical software MATLAB and they compared results with those obtained by finite element analysis software ANSYS [17]. Raki et al. derived equilibrium and stability equations of a rectangular plate made of functionally graded material (FGM) under thermal loads based on the higher order shear deformation plate theory [18]. Talha and Singh reported formulations based on higher order shear deformation theory with a considerable amendment in the transverse displacement using finite element method (FEM) [19]. Srinivas and Shiva Prasad focused on analysis of FGM flat plates under mechanical loading in order to understand the effect variation of material properties on structural response using ANSYS software [20]. Srinivas and Shiva Prasad focused on analysis of FGM flat plates under thermal loading in order to understand the effect variation of material properties on structural response. Results are compared to published results in order to show the accuracy of modelling FGMs using ANSYS software [21]. Alshorbagy et al. worked for the exact neutral plane position and evaluated FSDT model on a plate and presented the effect of heat source intensity

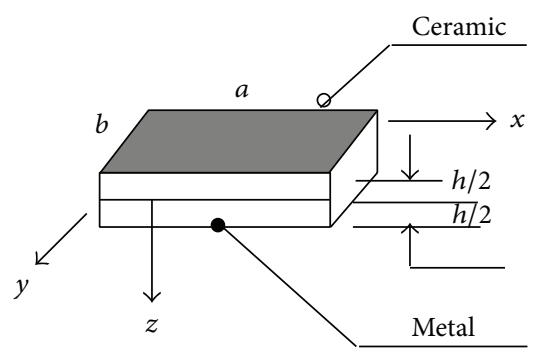

Figure 1: FGM plate.

for thermomechanical loading. They reported that FGMs provide a highly stable response for the thermal loading compared to that of the isotropic materials [22].

In the present study, the power law, sigmoid and exponential distribution, is considered for the volume fraction distributions of the functionally graded plates. The work includes parametric studies performed by varying volume fraction distributions and aspect ratio. The FGM plate is subjected to transverse UDL (uniformly distributed load) and point load and the response is analysed. The finite element software ANSYS APDL-13 is used for the modelling and analysis purpose.

\section{Material Gradient of FGM Plates}

The effective material properties like Young's modulus, Poisson's ratio, coefficient of thermal expansion, and thermal conductivity on the upper and lower surfaces are different but are predefined. However, Young's modulus and Poisson's ratio of the plates vary continuously only in the thickness direction (z-axis); that is, $=E(z), v=v(z)$.

The FGM plate of thickness " $h$ " is modelled usually with one side of the material as ceramic and the other side as metal (Figure 1). The " $z$ " is varying from " $h / 2$ " at top face, " 0 " at the middle of the thickness, to " $-h / 2$ " at bottom face. However, Young's moduli in the thickness direction of the FGM plates vary with power law functions (P-FGM), exponential functions (E-FGM), or sigmoid functions (SFGM). A mixture of the two materials composes the throughthe-thickness characteristics.

2.1. Power Law Function (P-FGM). The material properties of a P-FGM can be determined by the rule of mixture:

$$
P(z)=\left(P_{t}-P_{b}\right) V_{f}+P_{b}
$$

where $P$ denotes a generic material property like modulus, $P_{t}$ and $P_{b}$ denote the property of the top and bottom faces of the plate, and $V_{f}$ is volume fraction.

Material properties are dependent on the volume fraction $\left(V_{f}\right)$ of P-FGM which obeys power law as depicted in

$$
V_{f}=\left(\frac{z}{h}+\frac{1}{2}\right)^{n}
$$

where $n$ is a parameter that dictates the material variation profile through the thickness known as the volume fraction 


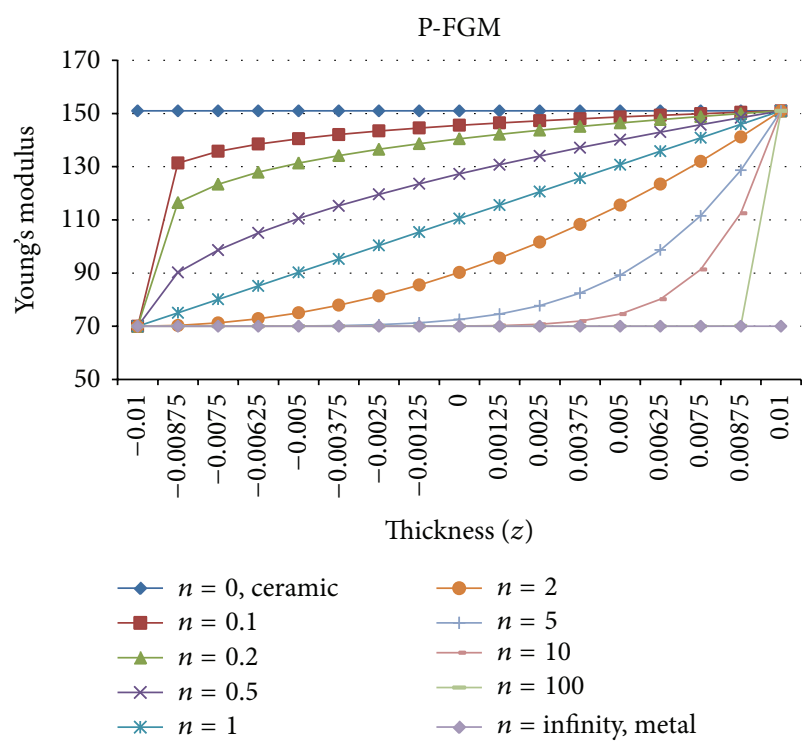

Figure 2: Variation of Young's modulus in a P-FGM with " $n$.”

exponent. At the bottom face, $(z / h)=-1 / 2$; hence $V_{f}=0$ and $P(z)=P_{b}$, and at top face, $(z / h)=1 / 2$; hence $V_{f}=1$ and $P(z)=P_{t}$.

At $n=0$ the plate is a fully ceramic plate while at $n=$ $\infty$ the plate is fully metal. The variation of Young's modulus in the thickness direction of the P-FGM plate is depicted in Figure 2, which shows that Young's modulus changes rapidly near the lowest surface for $n>1$ and increases quickly near the top surface for $n<1$.

2.2. Sigmoid Law. In the case of adding an FGM of a single power law function to the multilayered composite, stress concentrations appear on one of the interfaces where the material is continuous but changes rapidly. Therefore, Chung and Chi (2001) defined the volume fraction using two power law functions to ensure smooth distribution of stresses among all the interfaces. The two power law functions are defined by

$$
\begin{aligned}
& g_{1}(z)=1-\frac{1}{2}\left(\frac{h / 2-z}{h / 2}\right)^{p}, \quad \text { for } 0 \leq z \leq \frac{h}{2}, \\
& g_{2}(z)=\frac{1}{2}\left(\frac{h / 2+z}{h / 2}\right)^{p}, \quad \text { for }-\frac{h}{2} \leq z \leq 0 .
\end{aligned}
$$

By using the rule of mixture, Young's modulus of the S-FGM can be calculated by

$$
\begin{aligned}
& E(z)=g_{1}(z) E_{1}+\left[1-g_{1}(z)\right] E_{2}, \quad \text { for } 0 \leq z \leq \frac{h}{2}, \\
& E(z)=g_{2}(z) E_{1}+\left[1-g_{2}(z)\right] E_{2}, \quad \text { for }-\frac{h}{2} \leq z \leq 0 .
\end{aligned}
$$

The variation of Young's modulus in the thickness direction of the S-FGM plate is depicted in Figure 3, which shows that Young's modulus changes are gradual because of using two power law functions together as described above.

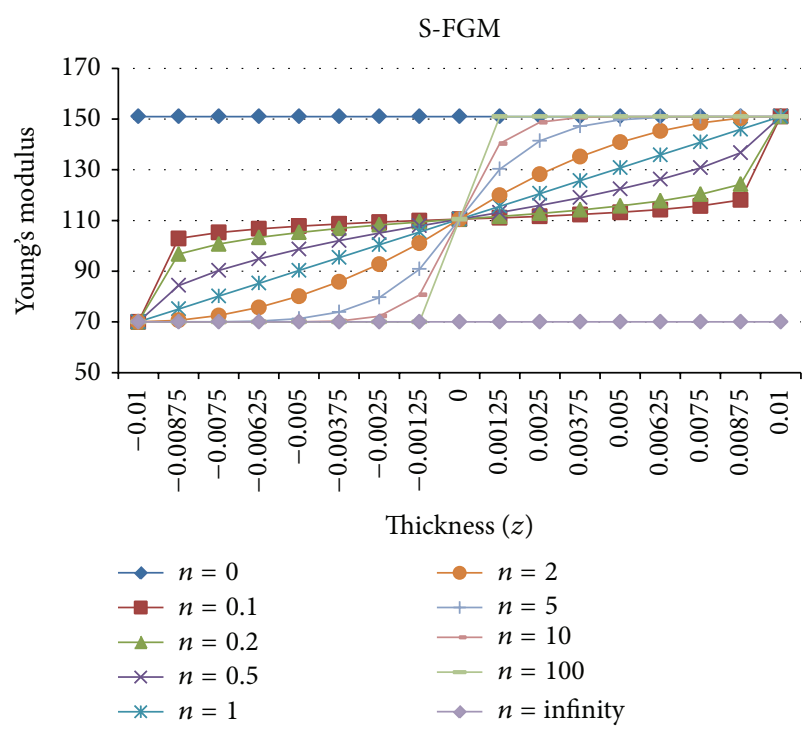

FIGURE 3: Variation of Young's modulus in a S-FGM with " $n$."

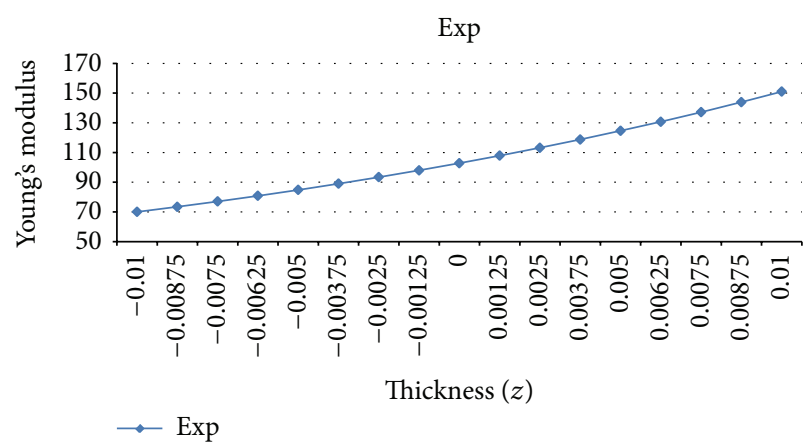

FIGURE 4: Variation of Young's modulus in a E-FGM plate.

2.3. Exponential Law. Many researchers used the exponential function to describe the material properties of FGMs as follows:

$$
E(z)=E_{2} e^{(1 / h) \ln \left(E_{1} / E_{2}\right)(z+h / 2)} .
$$

The material distribution in the E-FGM plates is plotted in Figure 4.

\section{Finite Element Modelling Technique}

The material properties of the FGM change throughout the thickness; the numerical model is to be broken up into various "layers" in order to capture the change in properties. These "layers" capture a finite portion of the thickness and are treated like isotropic materials. Material properties are calculated from the bottom surface using the various volume fraction distribution laws. The "layers" and their associated properties are then layered together to establish the throughthe-thickness variation of material properties. Although the layered structure does not reflect the gradual change in material properties, a sufficient number of "layers" can reasonably approximate the material gradation. In present analysis FGM 
plate has been modelled with 16 layers. In this paper, the finite element analysis has been carried out using minimum total potential energy formulation and modelling of FGM plate is carried out using ANSYS software. ANSYS offers a number of elements to choose from for the modelling of gradient materials. The FGM characteristics under mechanical loads have been studied on a flat plate which was modelled in 3D.

\section{Mechanical Analysis}

The mechanical analysis is conducted for FGM made of combination of metal and ceramic. The metal and ceramic chosen are aluminium and zirconia, respectively. Young's modulus for aluminium is $70 \mathrm{GPa}$ and that for zirconia is $151 \mathrm{GPa}$. Poisson's ratio for both of the materials was chosen to be 0.3 for simplicity. The FGM plate is simply supported at all of its edges (SSSS). The thickness of the plate $(h)$ is taken as $0.02 \mathrm{~m}$ and one of the side lengths $(b)$ is taken as $1 \mathrm{~m}$. The ratio of the plate side lengths is termed as aspect ratio $(a / b)$. The mechanical analysis was performed by applying uniformly distributed load (UDL) and also for the point load with varying aspect ratio $(a / b)$. The value of UDL and point load chosen was equal to $1 \times 10^{6} \mathrm{~N} / \mathrm{m}^{2}$. The gravity quite load is less as compared to the external load and is therefore neglected. The analysis is performed for E-FGM and for various values of the volume fraction exponent $(n)$ in P-FGM and S-FGM. The results are presented in terms of nondimensional parameters, that is, nondimensional deflection $\left(\overline{u_{z}}\right)$, nondimensional tensile stress $\left(\overline{\sigma_{x}}\right)$, and nondimensional shear stress $\left(\overline{\sigma_{x y}}\right)$.

The various nondimensional parameters used are nondimensional deflection

$$
\overline{u_{z}}=\frac{\left(100 E_{m} h^{3} u_{z}\right)}{\left(1-v^{2}\right) a^{4} p_{o}}
$$

and nondimensional stress

$$
\overline{\sigma_{x}}=\frac{\sigma h^{2}}{p_{o} a^{2}},
$$

where " $u_{z}$ " is maximum deflection, " $\sigma$ " is maximum stress, " $a$ " and " $b$ " are side lengths of plate, " $E_{m}$ " is Young's modulus of aluminium, and $p_{o}$ is applied load $\left(\mathrm{N} / \mathrm{m}^{2}\right)$.

4.1. Variation of Aspect Ratio $(a / b)$ with Uniformly Distributed Load. This section discusses the results of the analysis performed on FGM plate with varying aspect ratio subject to constant UDL. The results are presented in terms of nondimensional parameters.

4.1.1. Nondimensional Deflection $\left(\overline{u_{z}}\right)$. Figures 5,6 , and 7 show the variation of nondimensional deflection $\left(u_{z}\right)$ with aspect ratio $(a / b)$ for simply supported plates under UDL for P-FGM, S-FGM, and E-FGM, respectively. In case of PFGM and S-FGM the comparison of various values of volume fraction exponent $(n)$ has been presented. In case of E-FGM a single graph is obtained.

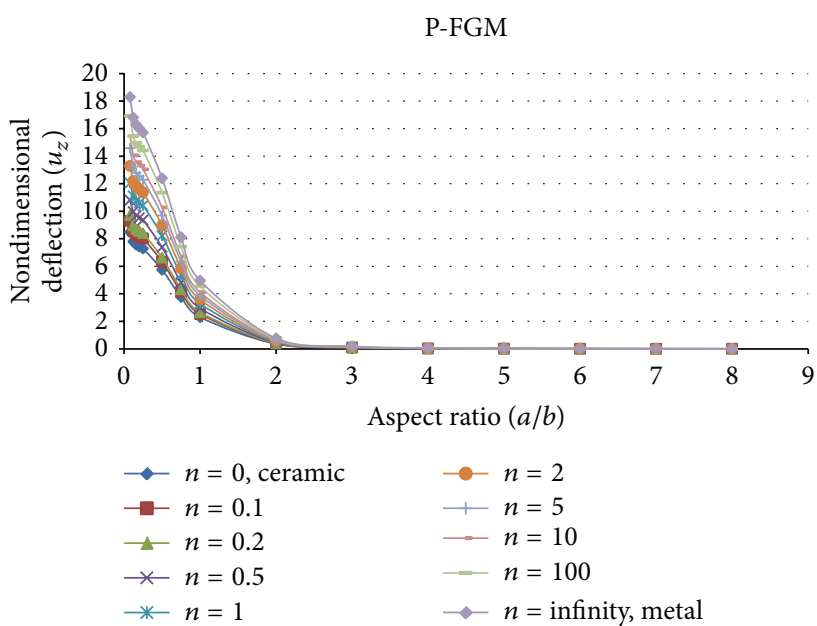

FIGURE 5: Nondimensional deflection $\left(u_{z}\right)$ versus aspect ratio $(a / b)$ for simply supported plates under UDL (P-FGM).

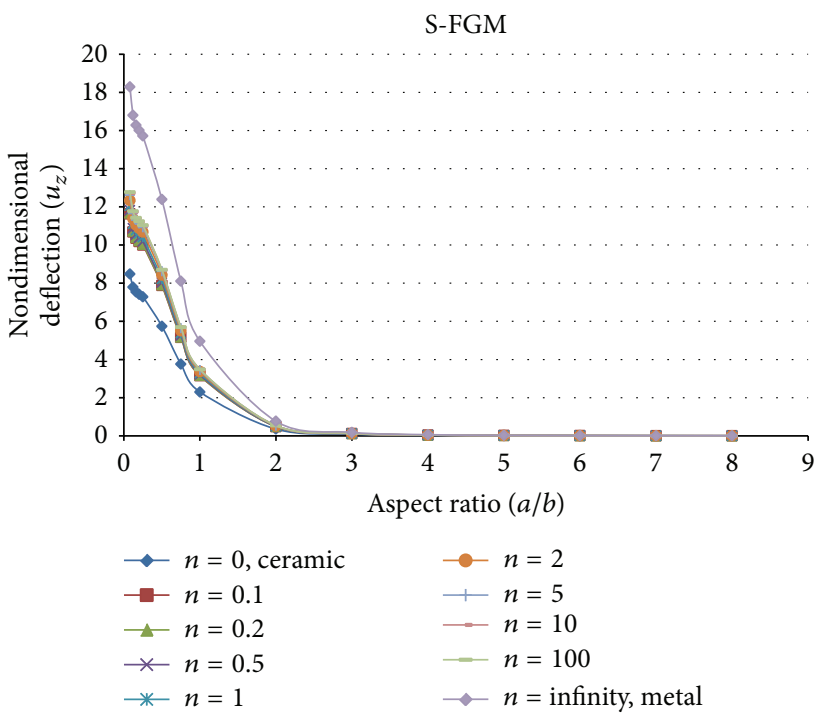

FIGURE 6: Nondimensional deflection $\left(u_{z}\right)$ versus aspect ratio $(a / b)$ for simply supported plates under UDL (S-FGM).

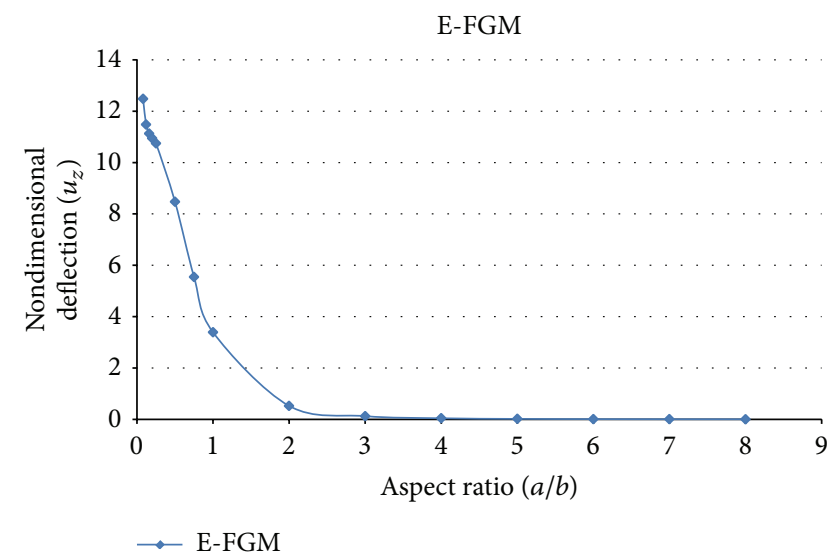

FIGURE 7: Nondimensional deflection $\left(u_{z}\right)$ versus aspect ratio $(a / b)$ for simply supported plates under UDL (E-FGM). 


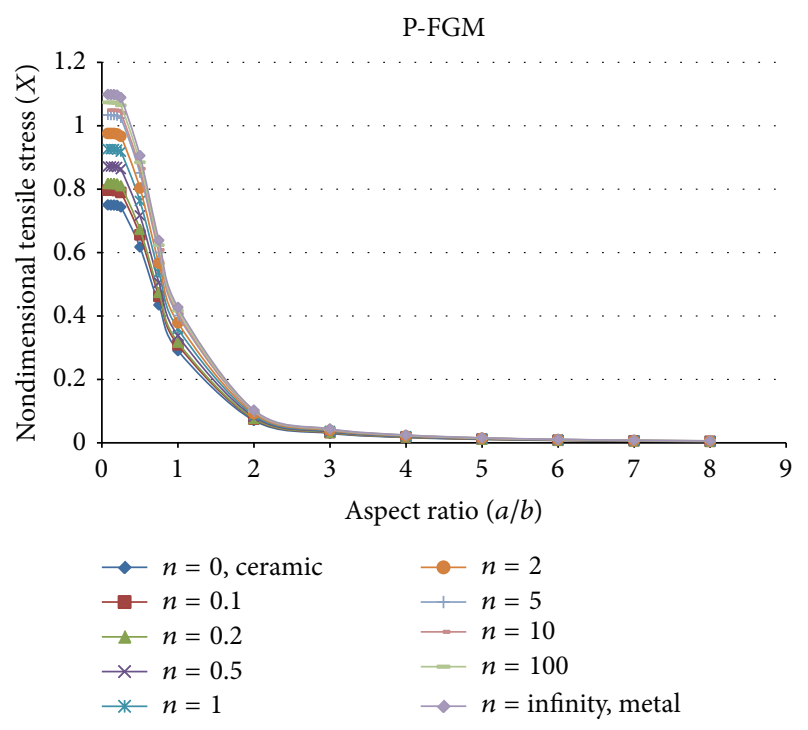

Figure 8: Nondimensional tensile stress $\left(\sigma_{x}\right)$ versus aspect ratio $(a / b)$ for simply supported plates under UDL (P-FGM).

It can be observed that

(a) the nondimensional deflection reduces as the aspect ratio increases up to 3 and it becomes constant as the aspect ratio is increased beyond the value 3 . The nondimensional deflection reduces steeply up to aspect ratio 3;

(b) the nondimensional deflection is maximum for the case of pure metal $(n=\infty)$ and is minimum for the case of pure ceramic $(n=0)$. As the " $n$ " increases the nondimensional deflection increases. This is due to the fact that the bending stiffness is the maximum for ceramic plate, while it is minimum for metallic plate, and degrades continuously as $n$ increases. The nondimensional deflection for S-FGM remains closer for various values of " $n$ " as compared to that of the PFGM.

4.1.2. Nondimensional Tensile Stress $\left(\overline{\sigma_{x}}\right)$. Figures 8,9 , and 10 show the variation of nondimensional tensile stress $\left(\overline{\sigma_{x}}\right)$ with aspect ratio $(a / b)$ for simply supported plates under UDL for P-FGM, S-FGM, and E-FGM, respectively. In case of PFGM and S-FGM the comparison of various values of volume fraction exponent $(n)$ has been presented. In case of E-FGM a single graph is obtained.

It can be observed that

(a) the nondimensional tensile stress does not have significant change for the aspect ratio up to 0.25 . The nondimensional tensile stress reduces steeply between aspect ratios 0.25 and 2 . The nondimensional tensile stress reduces as the aspect ratio increases and it becomes constant as the aspect ratio is increased beyond the value 6 ;

(b) the nondimensional tensile stress is maximum for the case of pure metal $(n=\infty)$ and minimum for the case

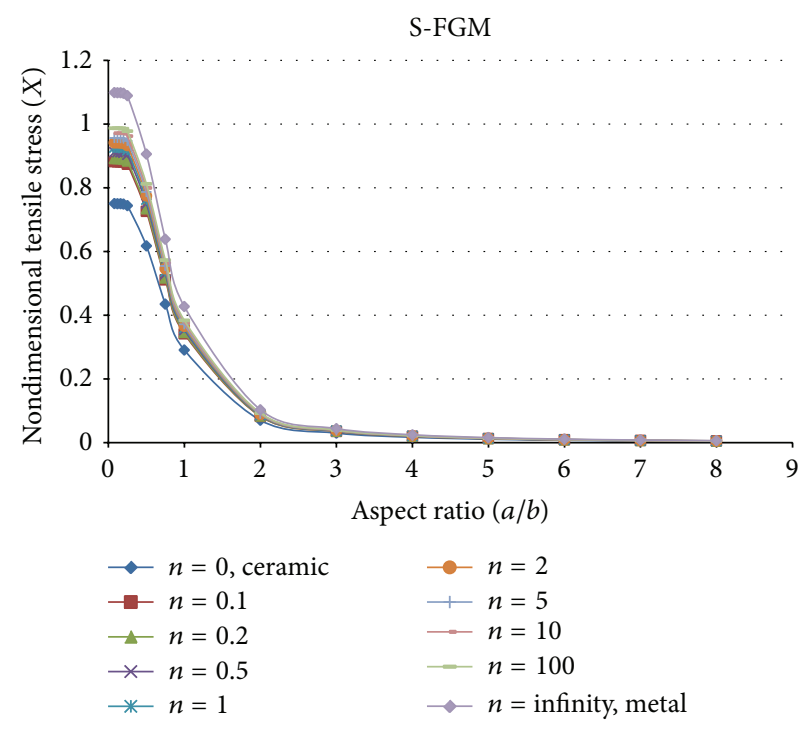

FIGURE 9: Nondimensional tensile stress $\left(\sigma_{x}\right)$ versus aspect ratio $(a / b)$ for simply supported plates under UDL (S-FGM).

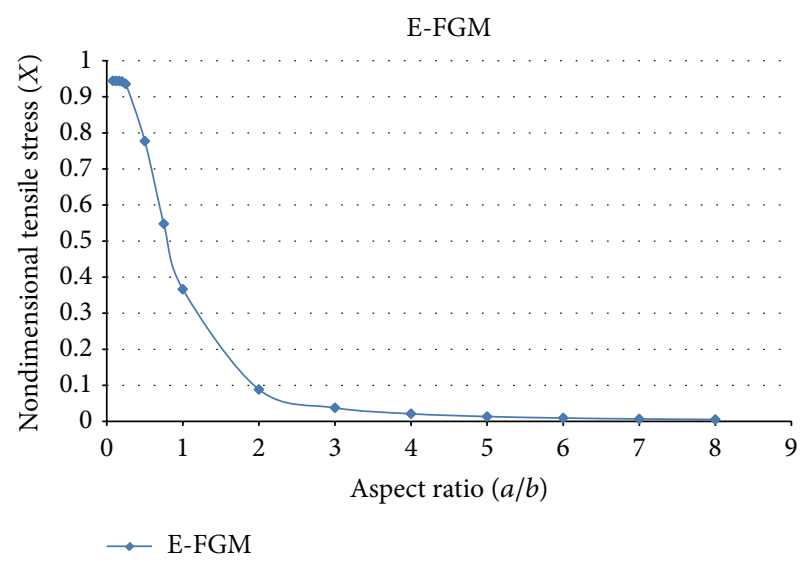

FIGURE 10: Nondimensional tensile stress $\left(\sigma_{x}\right)$ versus aspect ratio $(a / b)$ for simply supported plates under UDL (E-FGM).

of pure ceramic $(n=0)$. The nondimensional tensile stress for S-FGM remains closer for various values of " $n$ " as compared to that of the P-FGM.

4.1.3. Nondimensional Shear Stress $\left(\overline{\sigma_{x y}}\right)$. Figures 11,12 , and 13 show the variation of nondimensional shear stress $\left(\overline{\sigma_{x y}}\right)$ with aspect ratio $(a / b)$ for simply supported plates under UDL for P-FGM, S-FGM, and E-FGM, respectively. In case of PFGM and S-FGM the comparison of various values of volume fraction exponent $(n)$ has been presented. In case of E-FGM a single graph is obtained.

It can be observed that the nondimensional shear stress $\left(\sigma_{x y}\right)$ increases as the aspect ratio is increased, it reaches maximum value at aspect ratio 1, and it reduces as the aspect ratio increases beyond 1 . The nondimensional shear stress $\left(\sigma_{x y}\right)$ has a steep decline between aspect ratios 1 and 2 and a gradual decline after aspect ratio 2 . The nondimensional 


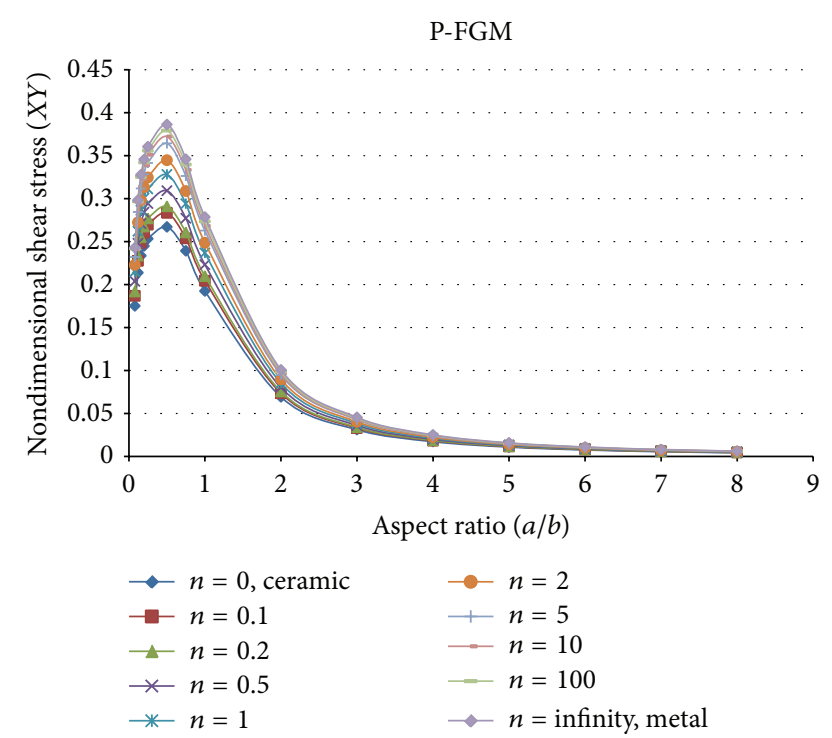

FIGURE 11: Nondimensional shear stress $\left(\sigma_{x y}\right)$ versus aspect ratio $(a / b)$ for simply supported plates under UDL (P-FGM).

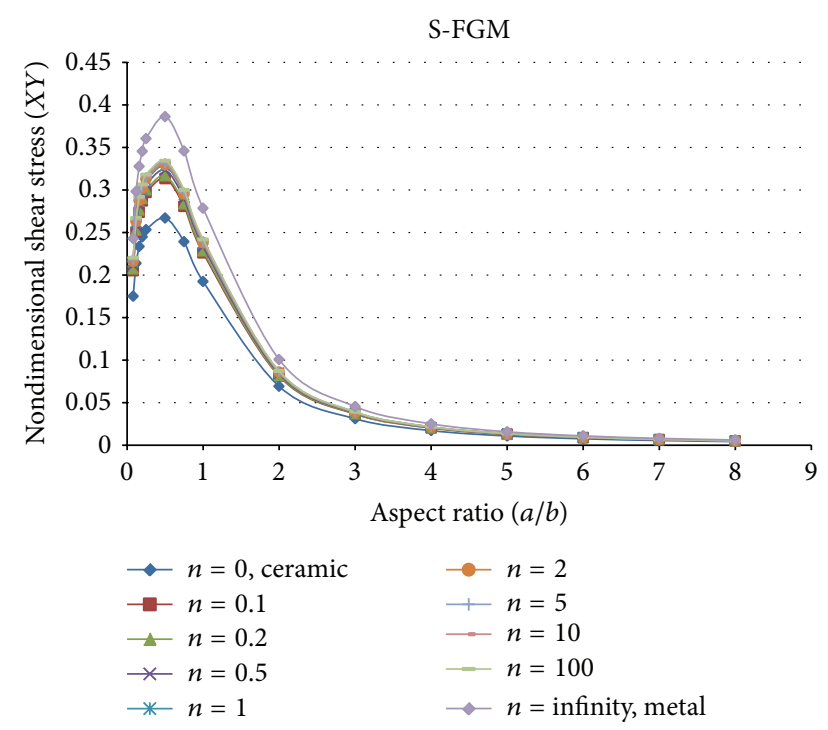

FIGURE 12: Nondimensional shear stress $\left(\sigma_{x y}\right)$ versus aspect ratio $(a / b)$ for simply supported plates under UDL (S-FGM).

shear stress $\left(\sigma_{x y}\right)$ is maximum for the case of pure metal $(n=\infty)$ and minimum for the case of pure ceramic $(n=0)$. The nondimensional shear stress $\left(\sigma_{x y}\right)$ for S-FGM remains closer for various values of " $n$ " as compared to that of the PFGM.

4.2. Comparison of P-FGM, S-FGM, E-FGM, Ceramic, and Metal. It is also interesting to see the comparison of various parameters like nondimensional deflection, tensile stress, shear stress, transverse strain, and shear strain for ceramic,

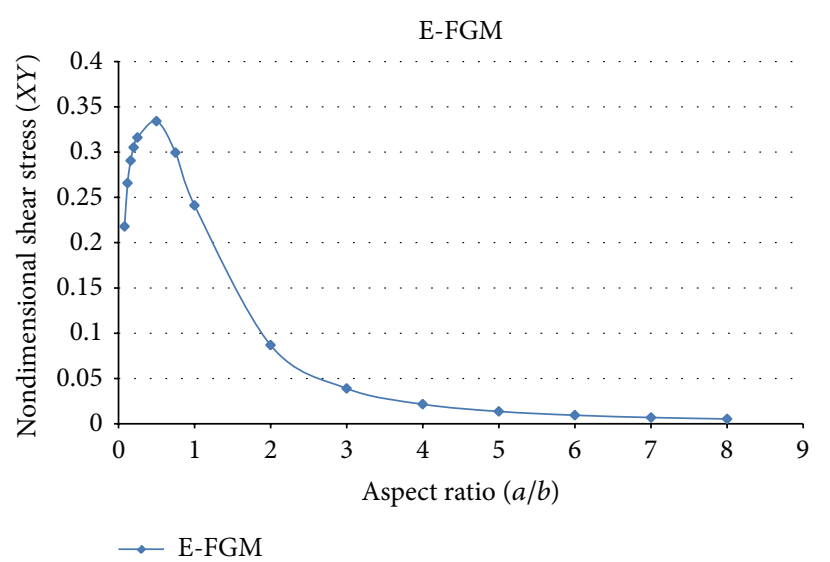

FIGURE 13: Nondimensional shear stress $\left(\sigma_{x y}\right)$ versus aspect ratio $(a / b)$ for simply supported plates under UDL (E-FGM).

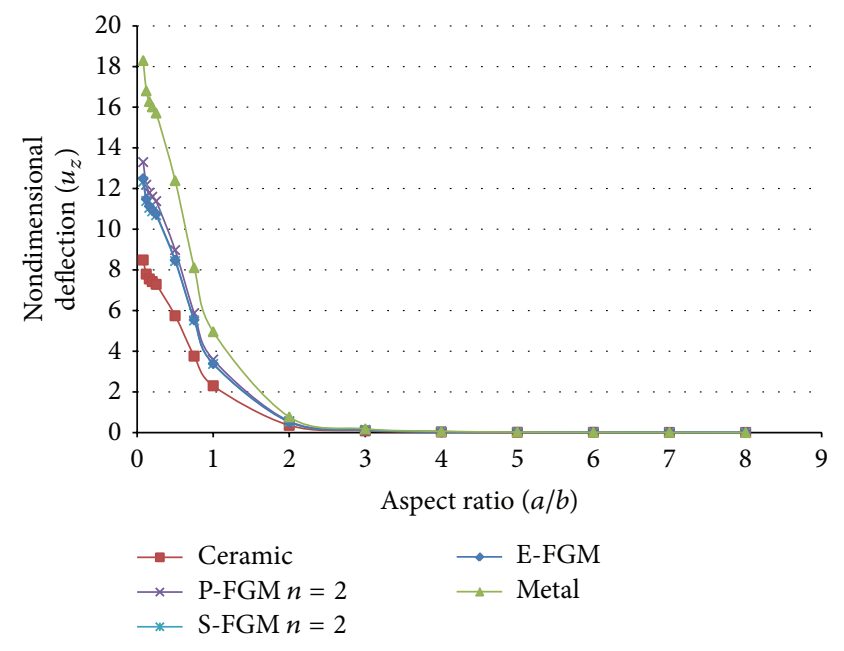

FIGURE 14: Nondimensional deflection $\left(u_{z}\right)$ versus aspect ratio $(a / b)$ for simply supported plates under UDL for various FGMs, ceramic, and metal.

metal, and FGMs following power law, sigmoid, and exponential distribution. Figures 14,15 , and 16 show the comparison graphs for pure ceramic $(n=0)$, pure metal $(n=\infty)$, P-FGM $(n=2)$, S-FGM $(n=2)$, and E-FGM.

\subsubsection{Nondimensional Deflection $\left(\overline{u_{z}}\right)$. See Figure 14.}

4.2.2. Nondimensional Tensile Stress $\left(\overline{\sigma_{x}}\right)$. See Figure 15.

\subsubsection{Nondimensional Shear Stress $\left(\overline{\sigma_{x y}}\right)$. See Figure 16. It is observed that}

(a) the characteristics of P-FGM and E-FGM are closer to each other as compared to that of S-FGM. The nondimensional tensile stress, shear stress, nondimensional deflection, transverse strain, and shear strain for the three FGMs are in between that of ceramic and metal. 


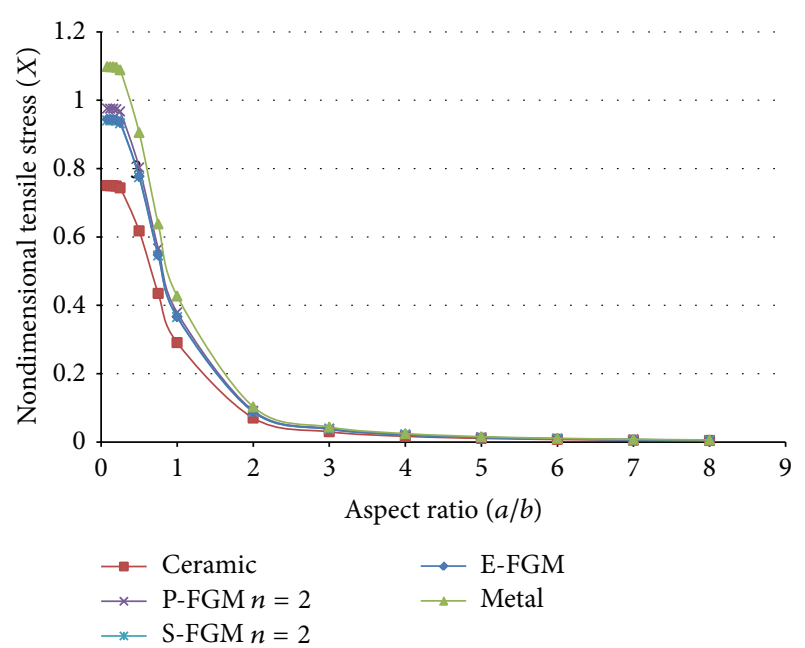

FIGURE 15: Nondimensional tensile stress $\left(\sigma_{x}\right)$ versus aspect ratio $(a / b)$ for simply supported plates under UDL for various FGMs, ceramic, and metal.

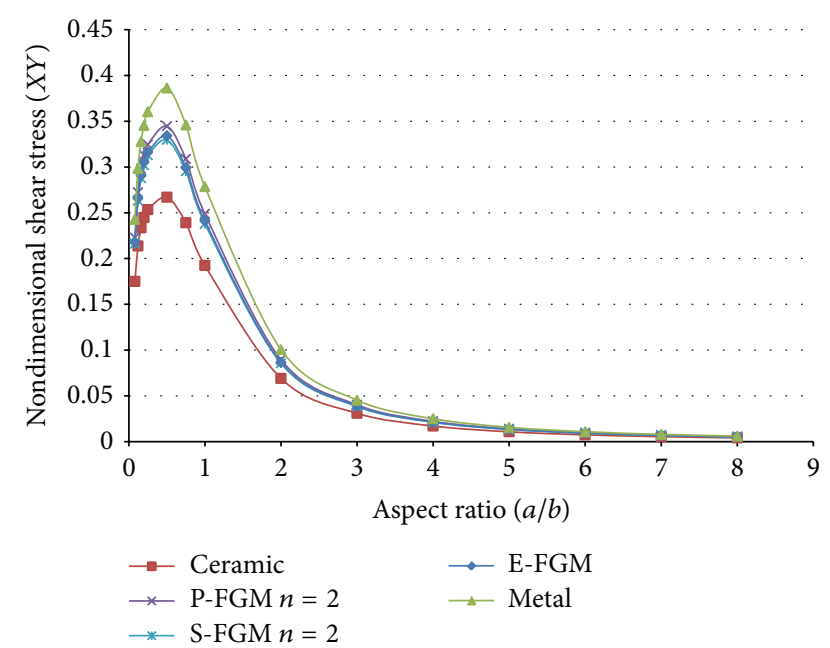

FIGURE 16: Nondimensional shear stress $\left(\sigma_{x y}\right)$ versus aspect ratio $(a / b)$ for simply supported plates under UDL for various FGMs, ceramic, and metal.

4.3. Variation of Aspect Ratio (a/b) with Mechanical Point Load. This section discusses the results of the analyses performed on FGM plate with varying aspect ratio and subject to constant point load acting at the geometric center of the plate. The results are presented in terms of nondimensional parameters, that is, nondimensional deflection $\left(\overline{u_{z}}\right)$, nondimensional tensile stress $\left(\overline{\sigma_{x}}\right)$, and nondimensional shear stress $\left(\overline{\sigma_{x y}}\right)$.

4.3.1. Nondimensional Deflection $(\overline{u z})$. Figures 17,18 , and 19 show the variation of nondimensional deflection $\left(u_{z}\right)$ with aspect ratio $(a / b)$ for simply supported plates under point load for P-FGM, S-FGM, and E-FGM, respectively. In case of P-FGM and S-FGM the comparison of various values of

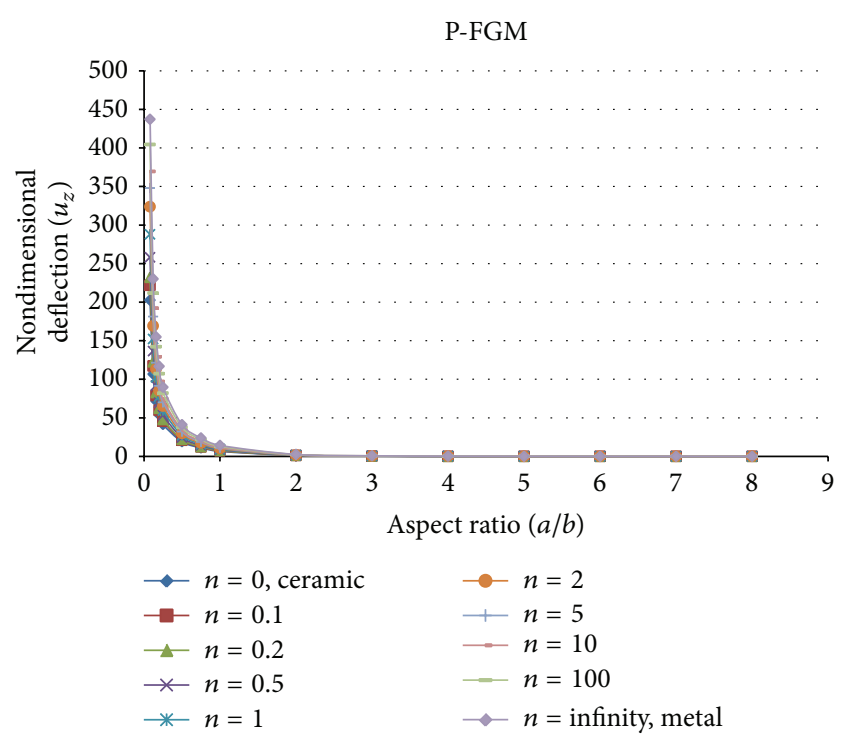

FIGURE 17: Nondimensional deflection $\left(u_{z}\right)$ versus aspect ratio $(a / b)$ for simply supported plates under point load (P-FGM).

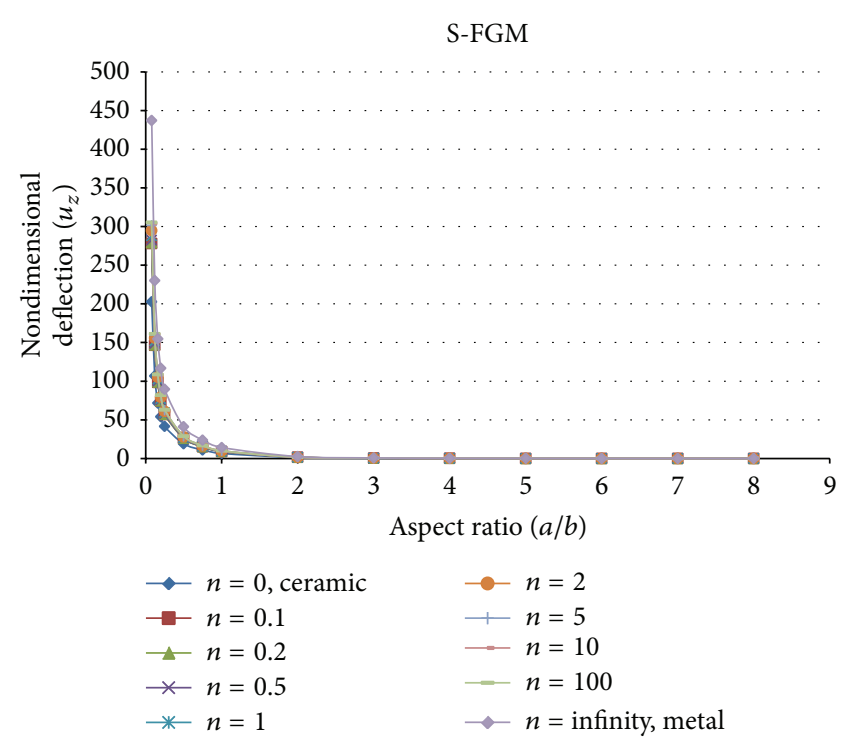

FIGURE 18: Nondimensional deflection $\left(u_{z}\right)$ versus aspect ratio $(a / b)$ for simply supported plates under point load (S-FGM).

volume fraction exponent $(n)$ has been presented. In case of E-FGM a single graph is obtained.

It can be observed that

(a) the nondimensional deflection reduces as the aspect ratio increases up to 3 and it becomes constant as the aspect ratio is increased beyond the value 3 . The nondimensional deflection reduces steeply up to aspect ratio 3;

(b) the nondimensional deflection is maximum for the case of pure metal $(n=\infty)$ and minimum for the case of pure ceramic $(n=0)$. As the " $n$ " increases the nondimensional deflection increases. This is due 


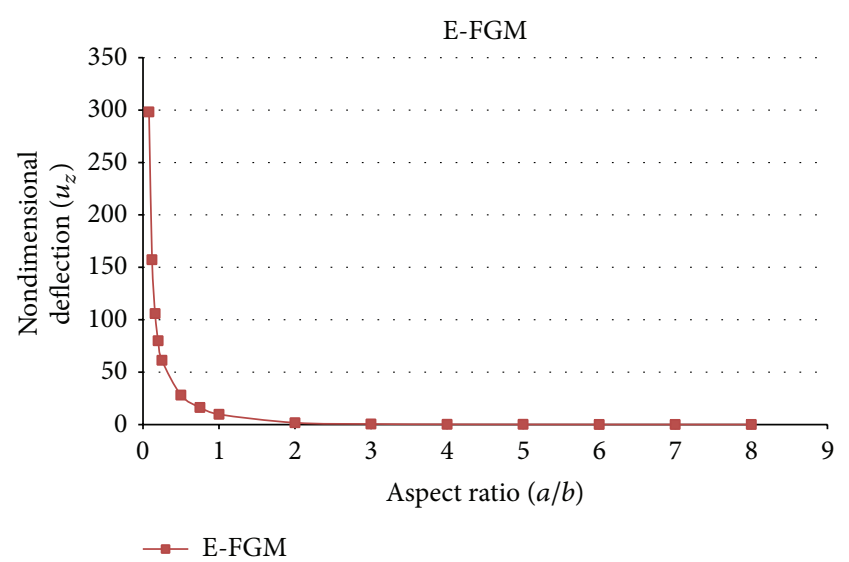

FIGURE 19: Nondimensional deflection $\left(u_{z}\right)$ versus aspect ratio $(a / b)$ for simply supported plates under point load (E-FGM).

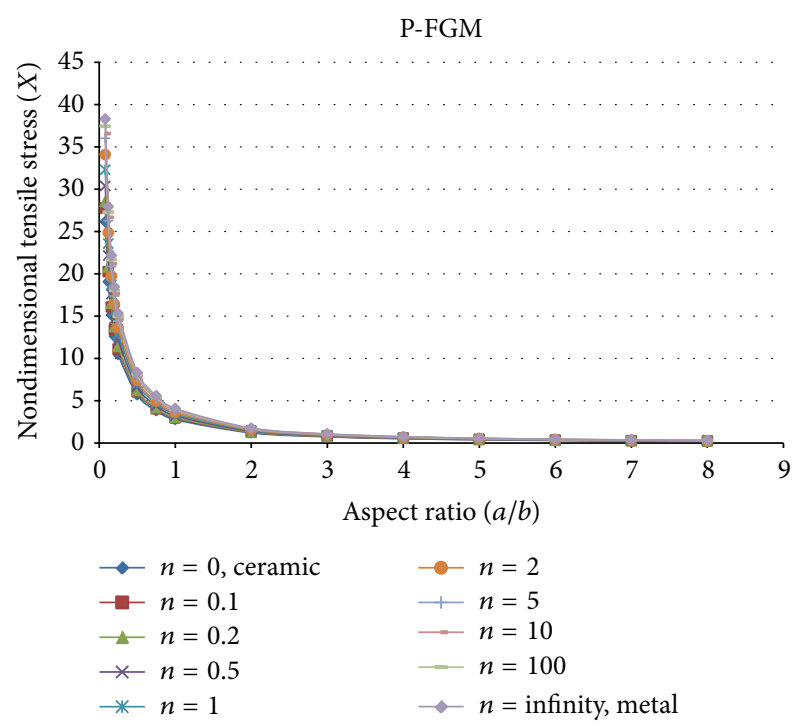

FIGURE 20: Nondimensional tensile stress $\left(\sigma_{x}\right)$ versus aspect ratio $(a / b)$ for simply supported plates under point load (P-FGM).

to the fact that the bending stiffness is maximum for ceramic plate, while minimum for metallic plate, and degrades continuously as $n$ increases. The nondimensional deflection for S-FGM remains closer for various values of " $n$ " as compared to that of the P-FGM.

4.3.2. Nondimensional Tensile Stress $\left(\overline{\sigma_{x}}\right)$. Figures 20, 21, and 22 show the variation of nondimensional tensile stress $\left(\overline{\sigma_{x}}\right)$ with aspect ratio $(a / b)$ for simply supported plates under point load for P-FGM, S-FGM, and E-FGM, respectively. In case of P-FGM and S-FGM the comparison of various values of volume fraction exponent $(n)$ has been presented. In case of E-FGM a single graph is obtained.

It can be observed that

(a) the nondimensional tensile stress reduces steeply up to aspect ratio 1 . The nondimensional tensile stress

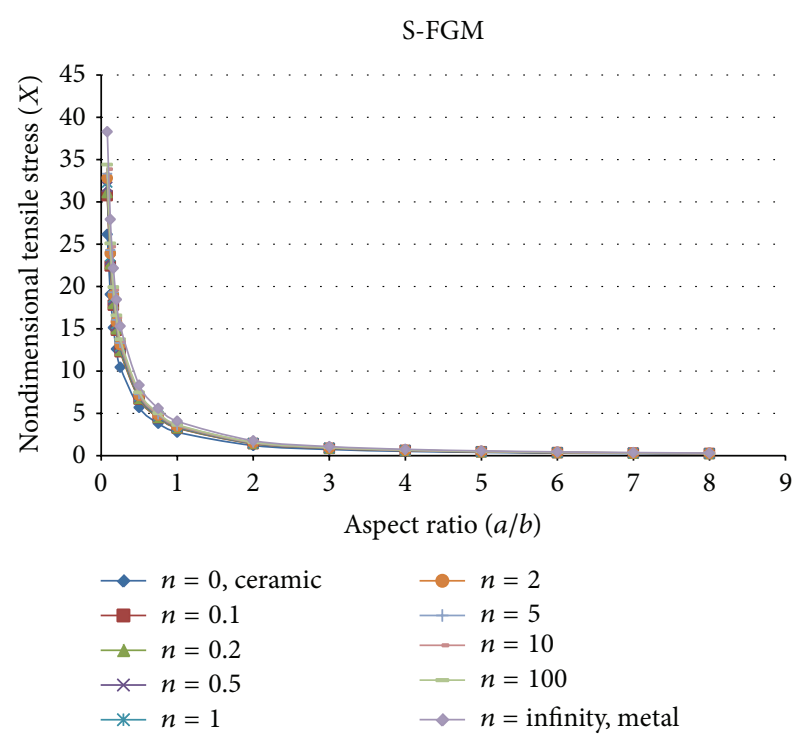

FIGURE 21: Nondimensional tensile stress $\left(\sigma_{x}\right)$ versus aspect ratio $(a / b)$ for simply supported plates under point load (S-FGM).

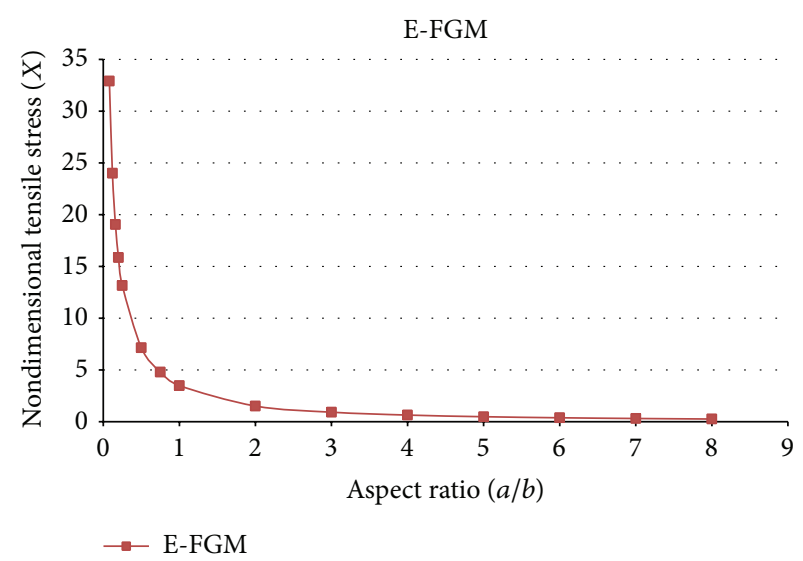

FIGURE 22: Nondimensional tensile stress $\left(\sigma_{x}\right)$ versus aspect ratio $(a / b)$ for simply supported plates under point load (E-FGM).

reduces as the aspect ratio increases and it becomes constant as the aspect ratio is increased beyond the value 6 ;

(b) the nondimensional tensile stress is maximum for the case of pure metal $(n=\infty)$ and minimum for the case of pure ceramic $(n=0)$. The nondimensional tensile stress for S-FGM remains closer for various values of " $n$ " as compared to that of the P-FGM.

4.3.3. Nondimensional Shear Stress $\left(\overline{\sigma_{x y}}\right)$. Figures 23, 24, and 25 show the variation of nondimensional shear stress $\left(\overline{\sigma_{x y}}\right)$ with aspect ratio $(a / b)$ for simply supported plates under point load for P-FGM, S-FGM, and E-FGM, respectively. In case of P-FGM and S-FGM the comparison of various values of volume fraction exponent $(n)$ has been presented. In case of E-FGM a single graph is obtained. 


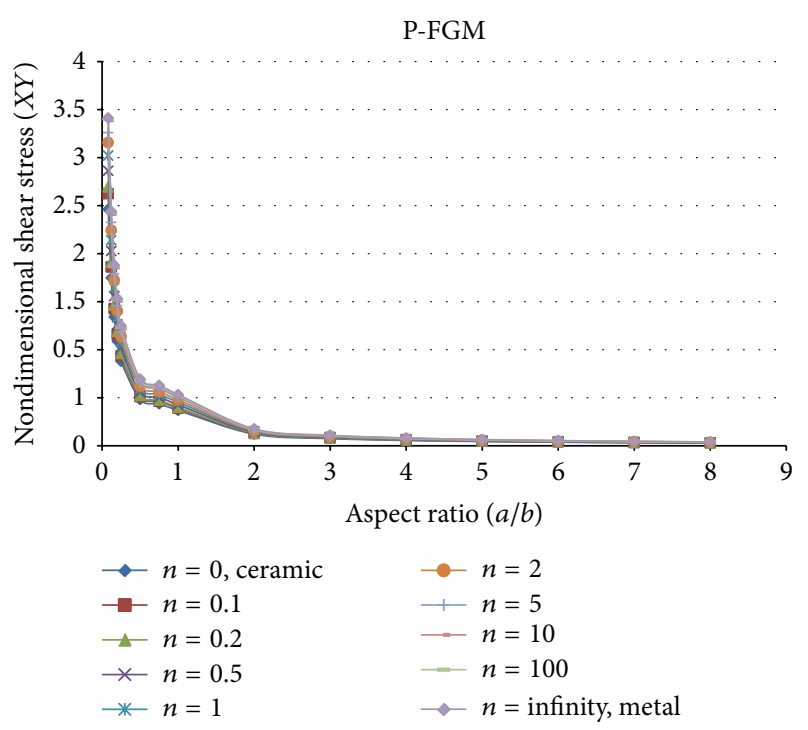

FIGURE 23: Nondimensional shear stress $\left(\sigma_{x y}\right)$ versus aspect ratio $(a / b)$ for simply supported plates under point load (P-FGM).

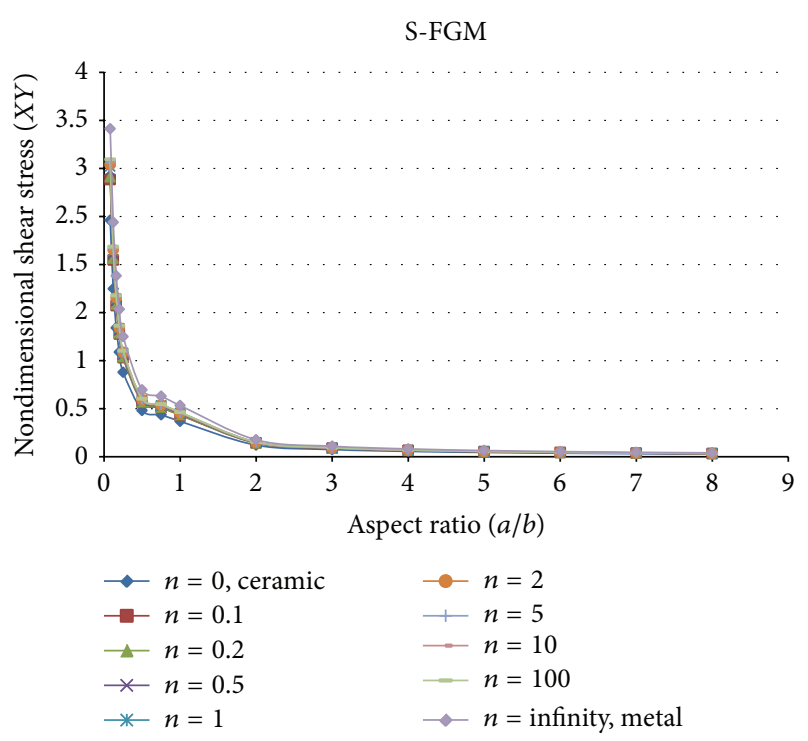

FIgURE 24: Nondimensional shear stress $\left(\sigma_{x y}\right)$ versus aspect ratio $(a / b)$ for simply supported plates under point load (S-FGM).

It can be observed that the nondimensional shear stress $\left(\sigma_{x y}\right)$ has a steep decline up to aspect ratio 1 and a gradual decline after aspect ratio 1 . The nondimensional shear stress $\left(\sigma_{x y}\right)$ is maximum for the case of pure metal $(n=\infty)$ and minimum for the case of pure ceramic $(n=0)$. The nondimensional shear stress $\left(\sigma_{x y}\right)$ for S-FGM remains closer for various values of " $n$ " as compared to that of the P-FGM.

4.4. Comparison of P-FGM, S-FGM, E-FGM, Ceramic, and Metal. It is also interesting to see the comparison of various parameters like nondimensional deflection, tensile stress, shear stress, transverse strain, and shear strain for ceramic,

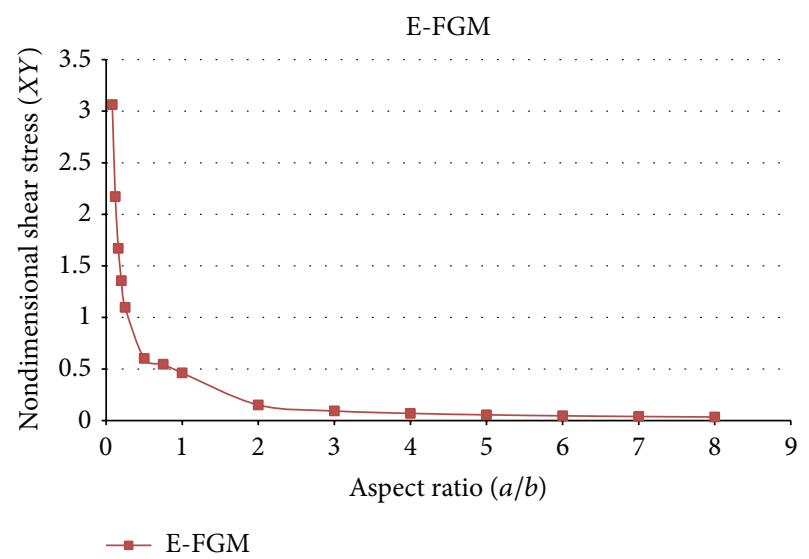

FIGURE 25: Nondimensional shear stress $\left(\sigma_{x y}\right)$ versus aspect ratio $(a / b)$ for simply supported plates under point load (E-FGM).

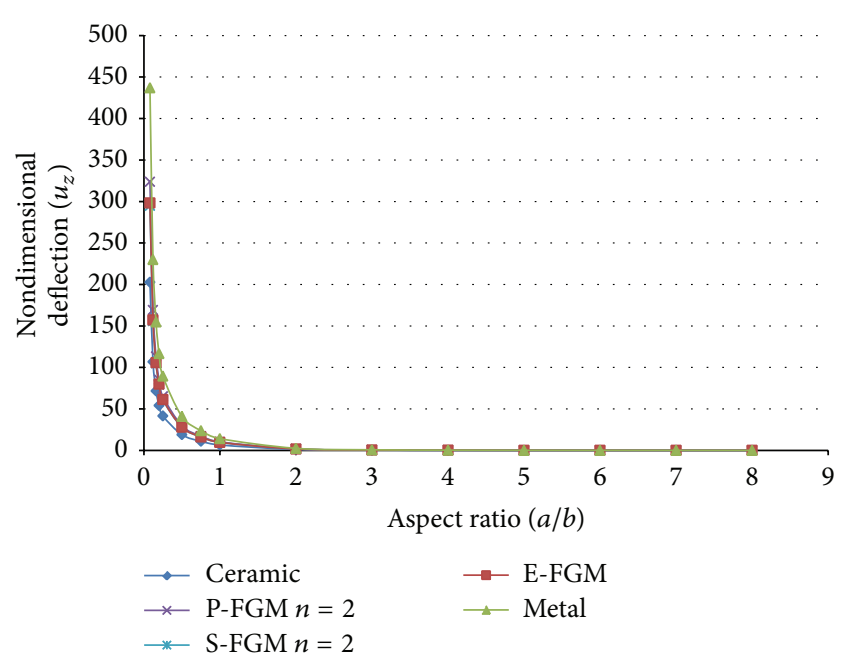

FIGURE 26: Nondimensional deflection $\left(u_{z}\right)$ versus aspect ratio $(a / b)$ for simply supported plates under point load for various FGMs, ceramic, and metal.

metal, and FGMs following power law, sigmoid, and exponential distribution. Figures 26,27 , and 28 show the comparison graphs for pure ceramic $(n=0)$, pure metal $(n=\infty)$, P-FGM $(n=2)$, S-FGM $(n=2)$, and E-FGM.

\subsubsection{Nondimensional Deflection $\left(\overline{u_{z}}\right)$. See Figure 26.}

It is observed that the characteristics of P-FGM and EFGM are closer to each other as compared to that of S-FGM. Also the nondimensional tensile stress, shear stress, nondimensional deflection, transverse strain, and shear strain for the three FGMs are in between that of ceramic and metal.

4.4.2. Nondimensional Tensile Stress $\left(\overline{\sigma_{x}}\right)$. See Figure 27.

4.4.3. Nondimensional Shear Stress $\left(\overline{\sigma_{x y}}\right)$. See Figure 28. 


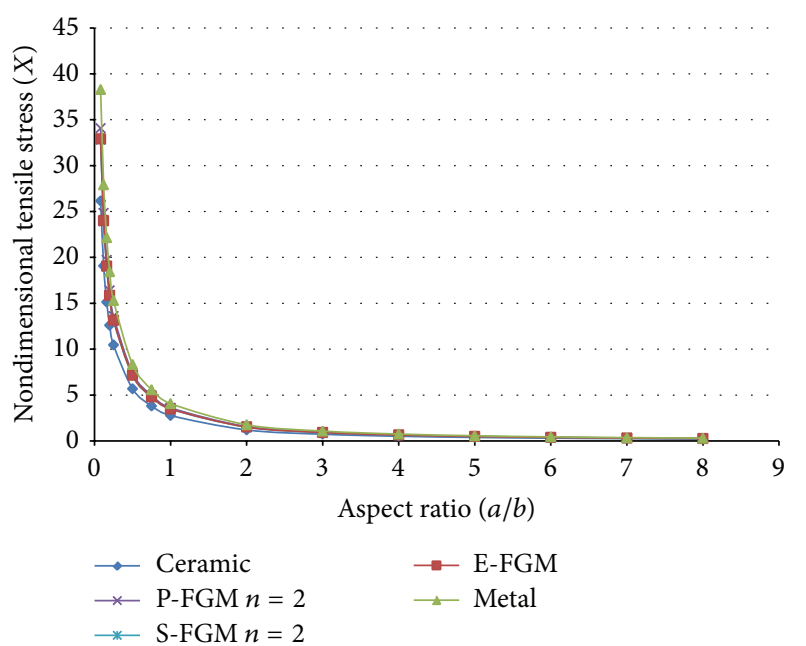

FIGURE 27: Nondimensional tensile stress $\left(\sigma_{x}\right)$ versus aspect ratio $(a / b)$ for simply supported plates under point load for various FGMs, ceramic, and metal.

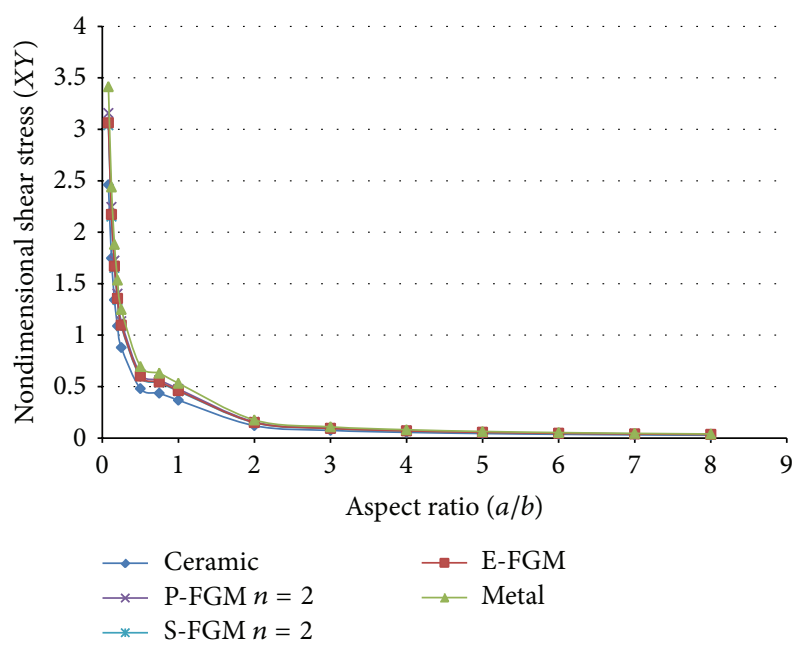

FIGURE 28: Nondimensional shear stress $\left(\sigma_{x y}\right)$ versus aspect ratio $(a / b)$ for simply supported plates under point load for various FGMs, ceramic, and metal.

\section{Conclusions and Future Scope}

Mechanical deformation of functionally graded ceramicmetal plates with varying aspect ratio is analysed. It is observed that the bending response of the functionally graded plate is intermediate to those of the metal and the ceramic plates. The nondimensional deflection is maximum for the case of pure metal $(n=\infty)$ and minimum for the case of pure ceramic $(n=0)$. As the " $n$ " increases the nondimensional deflection increases. The nondimensional tensile stress reduces as the aspect ratio increases and it becomes constant as the aspect ratio is increased beyond the value 6 . The nondimensional shear stress $\left(\sigma_{x y}\right)$ increases as the aspect ratio is increased, it reaches maximum value at aspect ratio 1 , and it reduces as the aspect ratio increases beyond 1 . The bending response for S-FGM remains closer for various values of " $n$ " as compared to that of the P-FGM. The bending response of E-FGM is nearer to the behavior of $\mathrm{P}$ FGM. The work can be extended for variation in load, loading pattern, and other ceramic metal combinations. Also thermal environment may be imposed in addition to the mechanical loading.

\section{Conflict of Interests}

The authors declare that there is no conflict of interests regarding the publication of this paper.

\section{References}

[1] G. N. Praveen and J. N. Reddy, "Nonlinear transient thermoelastic analysis of functionally graded ceramic-metal plates," International Journal of Solids and Structures, vol. 35, no. 33, pp. 4457-4476, 1998.

[2] J. N. Reddy, "Thermomechanical behavior of functionally graded materials," Final Report for AFOSR Grant F49620-951-0342, CML Report 98-01, 1998.

[3] Z. Q. Cheng and R. C. Batra, "Three-dimensional thermoelastic deformations of a functionally graded elliptic plate," Composites B: Engineering, vol. 31, no. 2, pp. 97-106, 2000.

[4] J. N. Reddy, "Analysis of functionally graded plates," International Journal for Numerical Methods in Engineering, vol. 47, no. 1-3, pp. 663-684, 2000.

[5] B. V. Sankar and J. T. Tzeng, "Thermal stresses in functionally graded beams," AIAA Journal, vol. 40, no. 6, pp. 1228-1232, 2002.

[6] L. F. Qian, R. C. Batra, and L. M. Chen, "Static and dynamic deformations of thick functionally graded elastic plates by using higher order shear and normal deformable plate theory and meshless local Petrov-Galerkin method," Composite Part B, vol. 35 , no. 6-8, pp. 685-697, 2004.

[7] A. J. M. Ferreira, R. C. Batra, C. M. C. Roque, L. F. Qian, and P. A. L. S. Martins, "Static analysis of functionally graded plates using third-order shear deformation theory and a meshless method," Composite Structures, vol. 69, no. 4, pp. 449-457, 2005.

[8] M. Tahani, M. A. Torabizadeh, and A. Fereidoon, "Non-linear response of functionally graded beams under transverse loads," in Proceedings of the 14th Annual International Techanical Engineering Conference, Isfahan University of Technology, Isfahan, Iran, May 2006.

[9] S. Chi and Y. Chung, "Mechanical behavior of functionally graded material plates under transverse load-part I: analysis," International Journal of Solids and Structures, vol. 43, no. 13, pp. 3657-3674, 2006.

[10] S.-H. Chi and Y.-L. Chung, "Mechanical behavior of functionally graded material plates under transverse load-Part II: numerical results," International Journal of Solids and Structures, vol. 43, no. 13, pp. 3675-3691, 2006.

[11] H. Wang and Q.-H. Qin, "Meshless approach for thermomechanical analysis of functionally graded materials," Engineering Analysis with Boundary Elements, vol. 32, no. 9, pp. 704-712, 2008.

[12] Y. M. Shabana and N. Noda, "Numerical evaluation of the thermomechanical effective properties of a functionally graded material using the homogenization method," International Journal of Solids and Structures, vol. 45, no. 11-12, pp. 3494-3506, 2008. 
[13] M. Mahdavian, "Buckling analysis of simply-supported functionally graded rectangular plates under non-uniform in-plane compressive loading," Journal of Solid Mechanics, vol. 1, no. 3, pp. 213-225, 2009.

[14] A. M. Zenkour and D. S. Mashat, "Thermal buckling analysis of ceramic-metal functionally graded plates," Natural Science, vol. 2, no. 9, pp. 968-978, 2010.

[15] S. S. Alieldin, A. E. Alshorbagy, and M. Shaat, "A first-order shear deformation finite element model for elastostatic analysis of laminated composite plates and the equivalent functionally graded plates," Ain Shams Engineering Journal, vol. 2, no. 1, pp. 53-62, 2011.

[16] K.-S. Na and J.-H. Kim, "Comprehensive studies on mechanical stress analysis of Functionally Graded Plates," World Academy of Science, Engineering and Technology, vol. 60, pp. 768-773, 2011.

[17] B. C. L. Vanam, M. Rajyalakshmi, and R. Inala, "Static analysis of an isotropic rectangular plate using finite element analysis (FEA)," Journal of Mechanical Engineering Research, vol. 4, no. 4, pp. 148-162, 2012.

[18] M. Raki, R. Alipour, and A. Kamanbedast, "Thermal buckling of thin rectangular FGM plate," World Applied Sciences Journal, vol. 16, no. 1, pp. 52-62, 2012.

[19] M. Talha and B. N. Singh, "Thermo-mechanical deformation behavior of functionally graded rectangular plates subjected to various boundary conditions and loadings," International Journal of Aerospace and Mechanical Engineering, vol. 6, p. 1, 2012.

[20] G. Srinivas and U. Shiva Prasad, "Simulation of traditional composites under mechanical loads," International Journal of Systems, Algorithms \& Applications, vol. 2, pp. 10-14, 2012.

[21] G. Srinivas and U. Shiva Prasad, "Simulation of traditional composites under thermal loads," Research Journal of Recent Sciences, vol. 2, pp. 273-278, 2013.

[22] A. E. Alshorbagy, S. S. Alieldin, M. Shaat, and F. F. Mahmoud, "Finite element analysis of the deformation of functionally graded plates under thermomechanical loads," Mathematical Problems in Engineering, vol. 2013, Article ID 569781, 13 pages, 2013. 

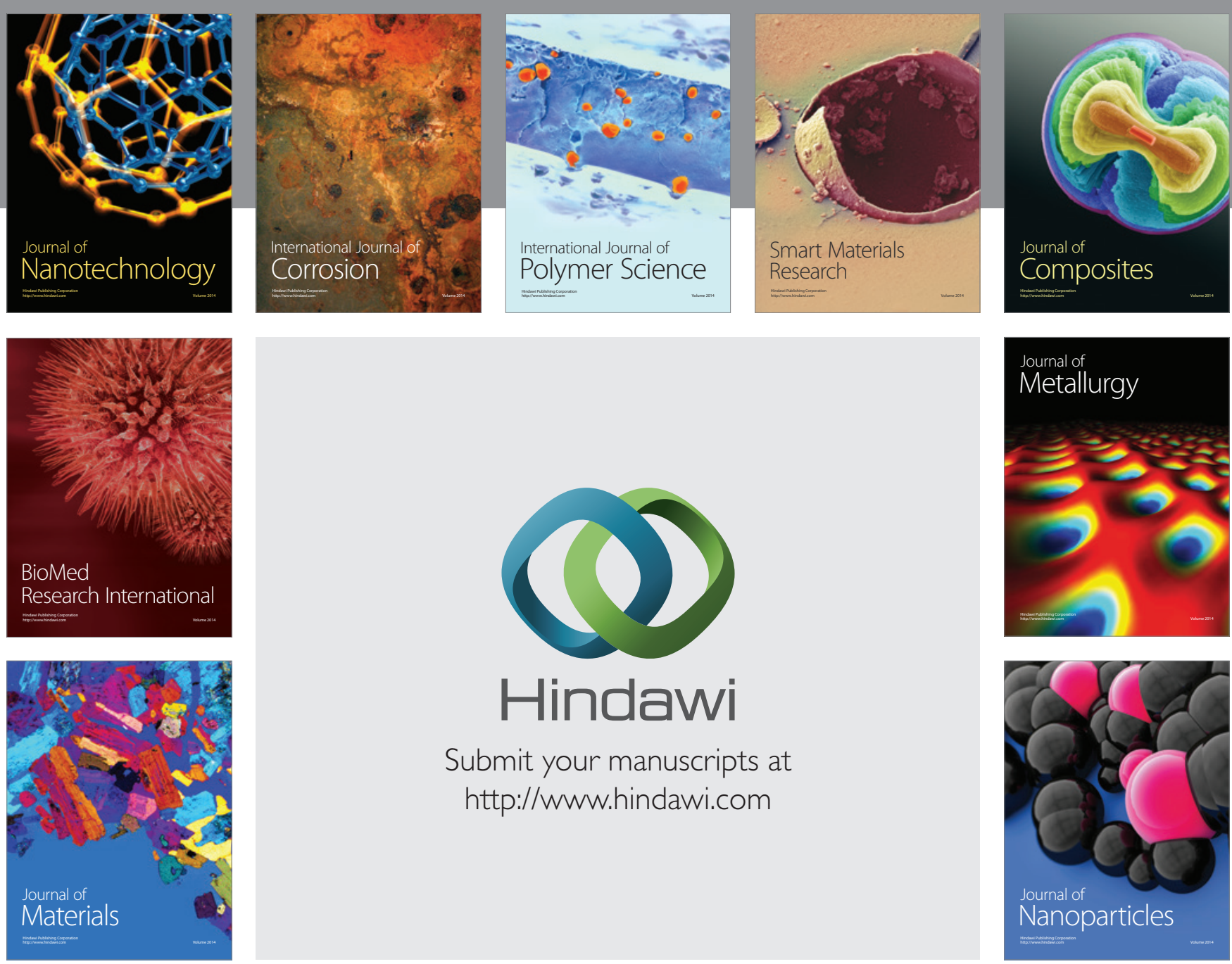

Submit your manuscripts at http://www.hindawi.com
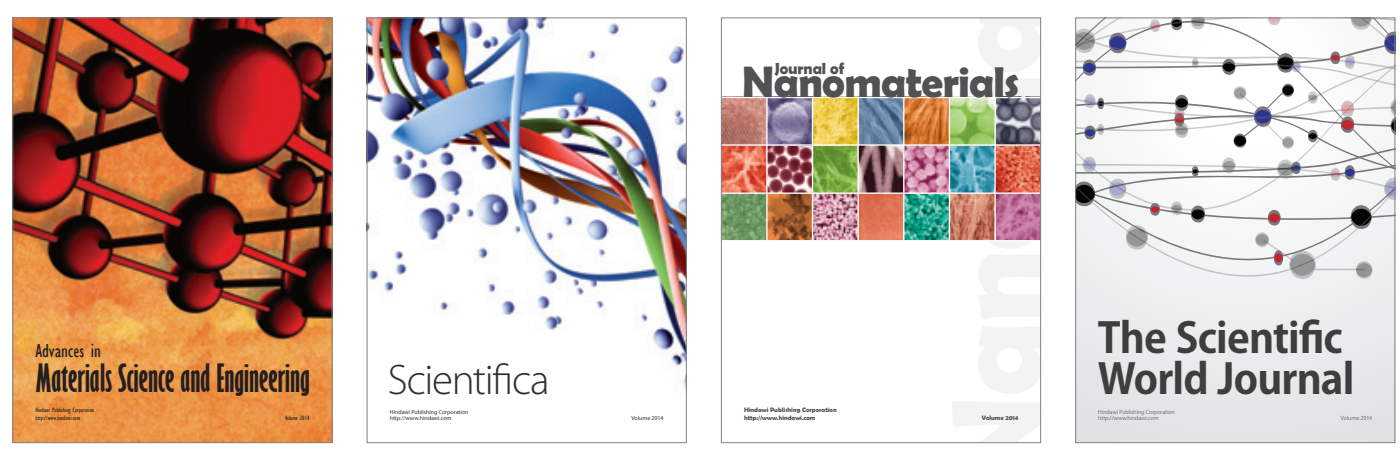

\section{The Scientific World Journal}
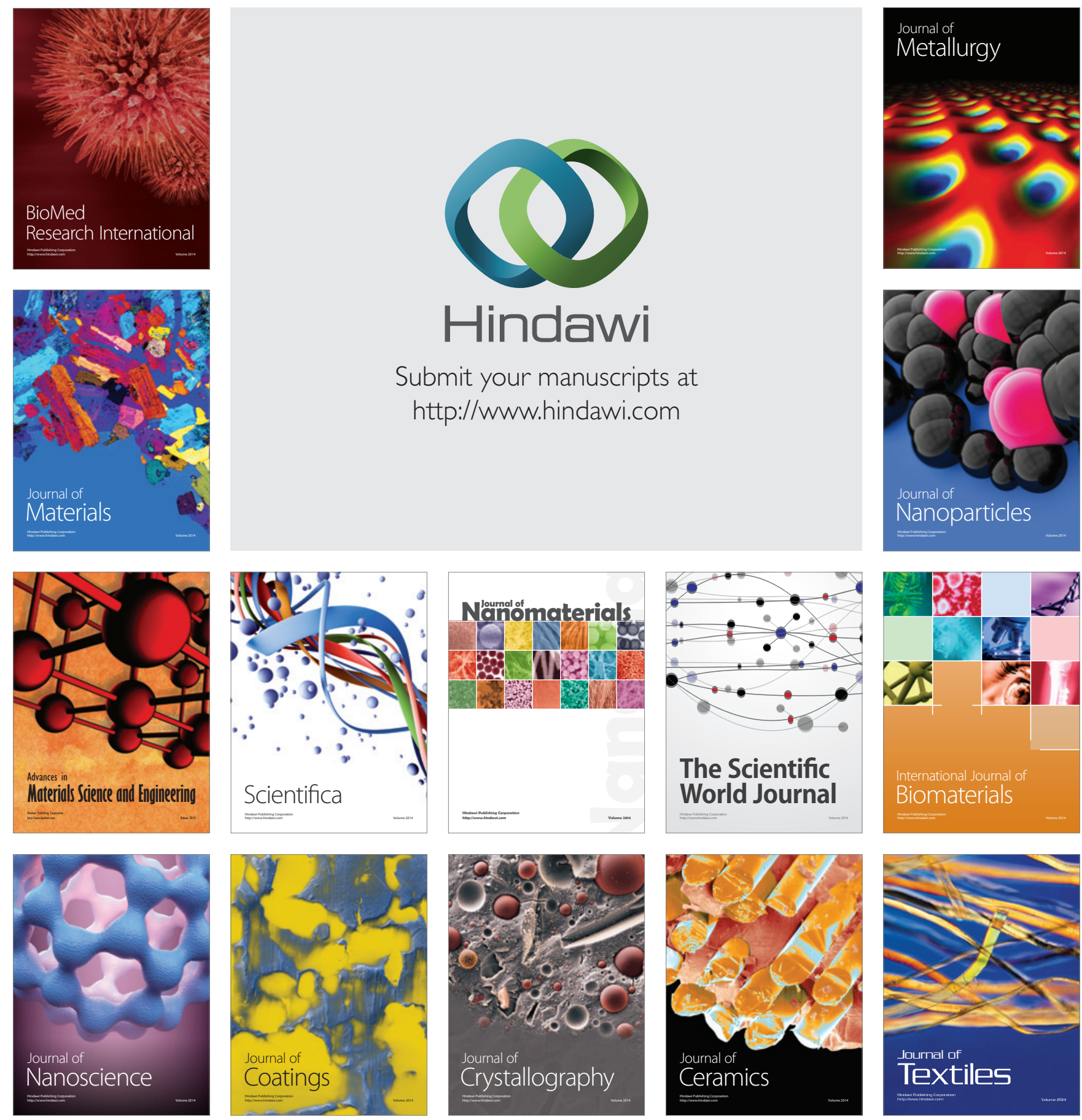